\title{
Article \\ ZnO Nanoparticles of Rubia cordifolia Extract Formulation Developed and Optimized with QbD Application, Considering Ex Vivo Skin Permeation, Antimicrobial and Antioxidant Properties
}

\author{
Jasmeet Kaur ${ }^{1}$, Md. Khalid Anwer ${ }^{2}$, , Ali Sartaj ${ }^{3}$ D, Bibhu Prasad Panda ${ }^{4}$, Abuzer Ali ${ }^{5}$, \\ Ameeduzzafar Zafar ${ }^{6}$ (D), Vinay Kumar ${ }^{7}$ (D), Sadaf Jamal Gilani ${ }^{8}$, Chandra Kala ${ }^{9}$ and Mohamad Taleuzzaman ${ }^{10, *(D)}$
}

check for updates

Citation: Kaur, J.; Anwer, M.K.; Sartaj, A.; Panda, B.P.; Ali, A.; Zafar, A.; Kumar, V.; Gilani, S.J.; Kala, C.; Taleuzzaman, M. ZnO Nanoparticles of Rubia cordifolia Extract Formulation Developed and Optimized with QbD Application, Considering Ex Vivo Skin Permeation, Antimicrobial and Antioxidant Properties. Molecules 2022, 27, 1450. https://doi.org/ $10.3390 /$ molecules 27041450

Academic Editors: Ildikó Backset, Dániel Nemes and Andrea Penoni

Received: 31 December 2021 Accepted: 16 February 2022 Published: 21 February 2022

Publisher's Note: MDPI stays neutral with regard to jurisdictional claims in published maps and institutional affiliations.

Copyright: (C) 2022 by the authors. Licensee MDPI, Basel, Switzerland. This article is an open access article distributed under the terms and conditions of the Creative Commons Attribution (CC BY) license (https:// creativecommons.org/licenses/by/ $4.0 /)$.
1 Department of Pharmacognosy and Phytochemistry, School of Pharmaceutical Education and Research, Jamia Hamdard, New Delhi 110062, India; jasmeetkaur_sch@jamiahamdard.ac.in

2 Department of Pharmaceutics, College of Pharmacy, Prince Sattam bin Abdulaziz University, P.O. Box 173, Al-Kharj 11942, Saudi Arabia; m.anwer@psau.edu.sa

3 Department of Pharmaceutics, Faculty of Pharmacy, School of Pharmaceutical Education and Research, Jamia Hamdard, New Delhi 110062, India; sartaz005@gmail.com

4 Microbial and Pharmaceutical Biotechnology Laboratory, Department of Pharmacognosy and Phytochemistry, School of Pharmaceutical Education and Research, Jamia Hamdard, New Delhi 110062, India; bppanda@jamiahamdard.ac.in

5 Department of Pharmacognosy, College of Pharmacy, Taif University, P.O. Box 11099, Taif-21944, Saudi Arabia; abuali@tu.edu.sa

6 Department of Pharmaceutics, College of Pharmacy, Jouf University, Al-Jouf 72341, Saudi Arabia; zzafarpharmacian@gmail.com or azafar@ju.edu.sa

7 Department of Pharmacology, KIET School of Pharmacy, Delhi-NCR, Meerut Road (NH-58), Ghaziabad 201206, India; vinaykumarpatel@gmail.com

8 Department of Basic Health Sciences, Preparatory Year, Princess Nourah Bint Abdulrahman University, Riyadh 11671, Saudi Arabia; SJGlani@pnu.edu.sa

9 Department of Pharmacology, Faculty of Pharmacy, Maulana Azad University, Village Bujhawar, Tehsil Luni, Jodhpur 342802, India; ckpharmacology@gmail.com

10 Department of Pharmaceutical Chemistry, Faculty of Pharmacy, Maulana Azad University, Village Bujhawar, Tehsil Luni, Jodhpur 342802, India

* Correspondence: zzaman007@gmail.com; Tel.: +91-725-1892-850

\begin{abstract}
The objective of the current research is to develop ZnO-Manjistha extract (ZnO-MJE) nanoparticles (NPs) and to investigate their transdermal delivery as well as antimicrobial and antioxidant activity. The optimized formulation was further evaluated based on different parameters. The ZnO-MJE-NPs were prepared by mixing $10 \mathrm{mM} \mathrm{ZnSO} 4 \cdot 7 \mathrm{H}_{2} \mathrm{O}$ and $0.8 \% w / v \mathrm{NaOH}$ in distilled water. To the above, a solution of $10 \mathrm{~mL} \mathrm{MJE}(10 \mathrm{mg})$ in $50 \mathrm{~mL}$ of zinc sulfate was added. Box-Behnken design (Design-Expert software 12.0.1.0) was used for the optimization of ZnO-MJE-NP formulations. The ZnO-MJE-NPs were evaluated for their physicochemical characterization, in vitro release activity, ex vivo permeation across rat skin, antimicrobial activity using sterilized agar media, and antioxidant activity by the DPPH free radical method. The optimized ZnO-MJE-NP formulation (F13) showed a particle size of $257.1 \pm 0.76 \mathrm{~nm}$, PDI value of $0.289 \pm 0.003$, and entrapment efficiency of $79 \pm 0.33 \%$. Drug release kinetic models showed that the formulation followed the Korsmeyer-Peppas model with a drug release of $34.50 \pm 2.56$ at $\mathrm{pH} 7.4$ in $24 \mathrm{~h}$. In ex vivo studies ZnO-MJE-NPs-opt permeation was $63.26 \%$. The antibacterial activity was found to be enhanced in ZnO-MJE-NPs-opt and antioxidant activity was found to be highest $(93.14 \pm 4.05 \%)$ at $100 \mu \mathrm{g} / \mathrm{mL}$ concentrations. The ZnO-MJE-NPsopt formulation showed prolonged release of the MJE and intensified permeation. Moreover, the formulation was found to show significantly $(p<0.05)$ better antimicrobial and antioxidant activity as compared to conventional suspension formulations.
\end{abstract}

Keywords: ZnO-MJE nanoparticles; Box-Behnken design; permeation study; antimicrobial and antioxidant activity; in vitro release 


\section{Introduction}

Rubia cordifolia (Figure 1), a medicinal plant commonly known as Manjistha, has gained increased clinical attention because of its high therapeutic potential [1].

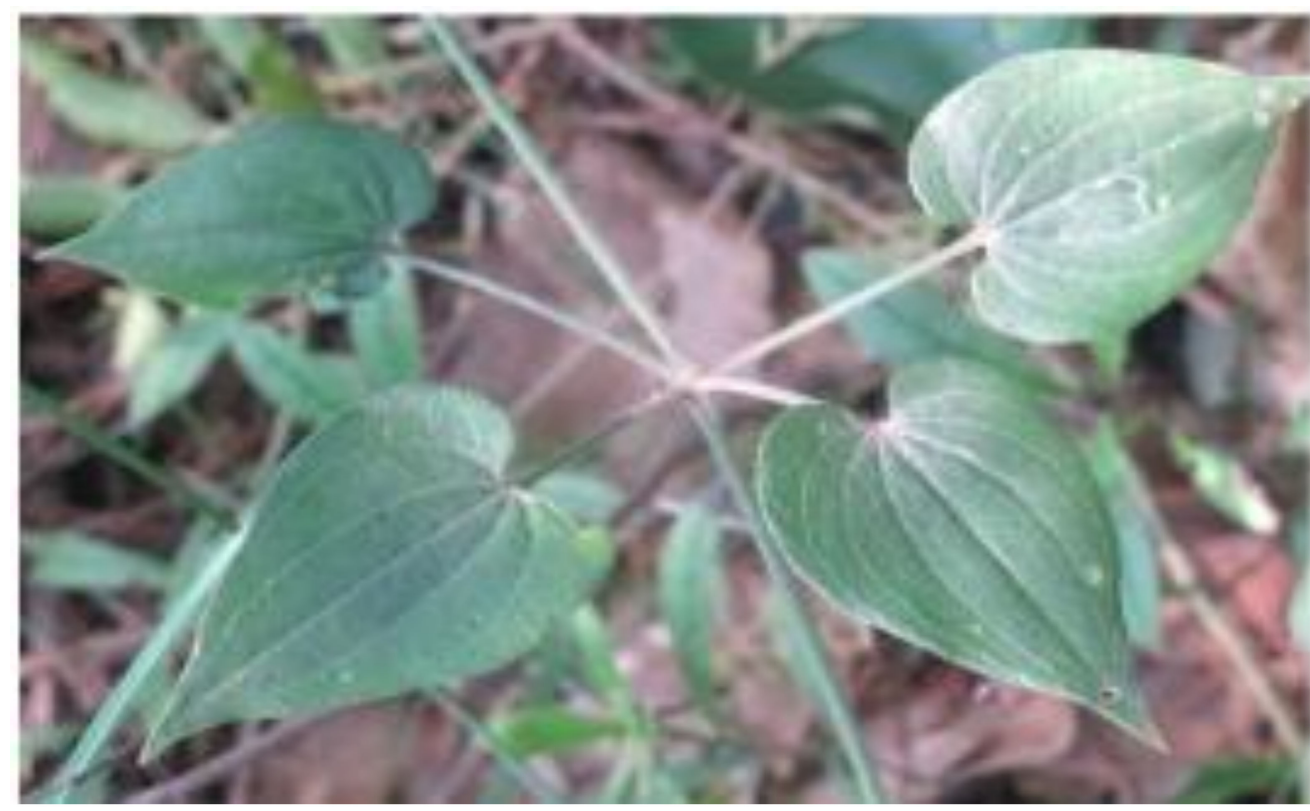

Figure 1. Rubia cordifolia (Image taken under Creative commons CC by 4.0 license).

Globally, it has been used for the conventional treatment of skin problems/disorders, stimulation of lymphatic flow, and blood disorders [2]. The root of the plant has been used traditionally for the treatment of rheumatism, menstrual disorders, jaundice, urinary disorders, renal stones, skin disorders, and blood detoxification. Previous studies have reported its antioxidant activity and enhanced production of antioxidant markers such as superoxide dismutase, catalase, and glutathione [3,4], along with the anti-inflammatory activity of Manjistha extract (MJE) [5,6]. Besides its medicinal value, the plant is used in food, syrups, and medicated oils as a natural colorant. Moreover, the leaf extract is widely used for cataracts, eczema, psoriasis, and in the treatment of chikungunya fever. Herbal extracts containing flavonoids, tannins, and terpenoids are soluble in water but the drawback is low absorption, which affects the bioavailability and efficacy [6]. Nanotherapeutics is a desired drug-targeted goal to provide high safety and efficacy over the conventional system [7-9].

A nanocarrier delivery system has been adopted to overcome the disadvantages of repeated dosage administration [10]. Nanotechnology-based drug delivery systems including liposomes, ethosomes, niosomes, nano-emulsions, micro-emulsions, nanostructured lipid carriers, polymeric micelles, and inorganic nanoparticles have been reported to enhance the oral bioavailability of many medicines [11-15]. The nanoformulation size, charge, and surface morphology play important roles in the physicochemical properties and therapeutic potential of drugs [16]. A colloidal dispersion of nanoparticles formulates the nanosuspension and is stabilized by a surfactant [17]. Inorganic nanoparticles using $\mathrm{ZnO}$ have significant therapeutic potential. $\mathrm{ZnO}$ has various advantages like low cost, biocompatibility, nontoxicity, antimicrobial property, and high availability in nature [18]. The green synthesis of nanoparticles using Rubia cordifolia was reported earlier for zinc oxide nanoparticles (ZnO-NPs) and silver nanoparticles (Ag-NPs) with antibacterial activity $[19,20]$. Previous studies have reported that the $\mathrm{ZnO}$ nanoparticles can be used as an herbal bioactive compound to increase the therapeutic potential of plants like Calotropis procera [21], Poncirus trifoliata [22], and Artemisia annua [23].

The formulation development process uses optimization with the approach of quality by design $(\mathrm{QbD})$ to understand the better variable effects and robust quality of the product 
to confirm the target quality product profile. Design of experiment (DoE) requires critical parameters with fixed ranges to obtain design space (DS) based on the risk assessment process and formulation variables [24-27].

In the surface response methodology, the Box-Behnken design (BBD) includes powerful, effective, and systematic tools that lessen the time required for the development of pharmaceutical dosage forms with enhanced research output. BBD permits the designer to utilize three levels of each factor to properly achieve the quantification.

This current study focuses on the development of the formulation of ZnO-NPs of Manjistha extract. Optimization of the formulation was performed by Design-Expert software considering variable parameters such as particle size, \% entrapment efficiency, and polydispersity index (PDI), and the independent variables were the concentration of $\mathrm{ZnSO}_{4} \cdot 7 \mathrm{H}_{2} \mathrm{O}(\% \mathrm{w} / \mathrm{v})$, stirring speed (rpm), and ultrasonic time (minutes). Thereafter, the optimized formulation was analyzed for morphology, particle size, zeta potential, in vitro drug release, ex vivo skin study, stability study, and antimicrobial as well as anti-oxidant activities. The objective of the association of ex vivo study with antimicrobial and antioxidant activity was to enhance the therapeutic effect by increasing the drug release to reach systemic circulation quickly.

\section{Experimental Work}

\subsection{Materials}

Manjistha extract was procured from the Sunpure Research Incubation Center, Sunpure Extracts Pvt. Ltd. Delhi, India. The chemicals zinc sulfate $\left(\mathrm{ZnSO}_{4} \cdot 7 \mathrm{H}_{2} \mathrm{O}\right)$ and sodium hydroxide $(\mathrm{NaOH})$ were of analytical grade and were procured from SD Fine Chemical (Mumbai, India).

\subsection{Preparation of Nanoparticles}

The preparation of $\mathrm{ZnO}-\mathrm{NPs}$ of an aqueous MJE was reported previously [28]. A solution of zinc sulfate $\left(\mathrm{ZnSO}_{4} \cdot 7 \mathrm{H}_{2} \mathrm{O}\right)$ and sodium hydroxide $(\mathrm{NaOH})$ was prepared with a strength of $10 \mathrm{mM}(5.75 \% w / v$ and $0.8 \% w / v$ in distilled water, respectively) as shown in the Scheme 1. Ten milliliters of MJE $(1 \mathrm{mg} / \mathrm{mL})$ were transferred to $50 \mathrm{~mL}$ of zinc sulfate solution; then, $\mathrm{NaOH}$ was added dropwise until a white suspension of nanoparticles was produced. Nanoparticles were centrifuged at $5000 \mathrm{rpm}$ for $10 \mathrm{~min}$ and then stored in the refrigerator.

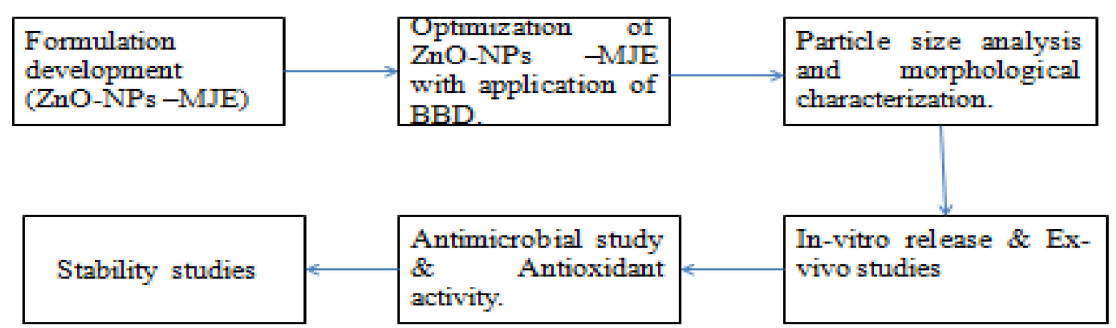

Scheme 1. Flow chart of work.

\subsection{Box-Behnken Design (BBD) Optimization}

The ZnO-MJE-NPs were optimized using Box-Behnken design (Design-Expert software version 12.0.1.0). Depending upon the preliminary study, the concentration of $\mathrm{ZnSO}_{4} \cdot 7 \mathrm{H}_{2} \mathrm{O}(\% \mathrm{w} / v)$, stirring speed (rpm), and ultrasonic time (minutes) were selected as the independent variables, and particle size, PDI, and entrapment efficiency were selected as dependent variables. The software found 13 formulations as expressed in Table 1 . The data of each response were fitted into different experimental design models for obtaining the best-fit model. The 3-D plot of each response was constructed, which showed the graphical presentation of independent variables over the responses $[29,30]$. 
Table 1. Observed responses of different formulation batches on the basis of independent variables.

\begin{tabular}{|c|c|c|c|c|c|c|}
\hline \multirow[b]{2}{*}{$\begin{array}{l}\text { Formulation } \\
\text { Code (FC) }\end{array}$} & \multicolumn{3}{|c|}{ Factor } & \multicolumn{3}{|c|}{ Response } \\
\hline & $\begin{array}{c}\mathrm{ZnSO}_{4} \cdot 7 \mathrm{H}_{2} \mathrm{O} \\
(\% w / v)\end{array}$ & $\begin{array}{l}\text { Ultrasonic Time } \\
(\min )\end{array}$ & $\begin{array}{c}\text { Stirring } \\
\text { Speed } \\
\text { (rpm) }\end{array}$ & $\begin{array}{c}\text { \% Entrapment } \\
\text { Efficiency } \pm \text { SD } \\
(\mathrm{n}=3)\end{array}$ & $\begin{array}{l}\text { Particle Size } \pm \text { SD } \\
\quad(\mathrm{n}=3) \mathrm{nm}\end{array}$ & $\begin{array}{l}\mathrm{PDI} \pm \mathrm{SD} \\
\quad(\mathrm{n}=3)\end{array}$ \\
\hline F1 & 4.75 & 2 & 500 & $81.6 \pm 0.17$ & $264.1 \pm 0.81$ & $0.291 \pm 0.001$ \\
\hline F2 & 6.75 & 2 & 500 & $82.3 \pm 0.05$ & $263.1 \pm 1.55$ & $0.292 \pm 0.002$ \\
\hline F3 & 4.75 & 4 & 500 & $82.85 \pm 0.13$ & $261.3 \pm 1.62$ & $0.294 \pm 0.002$ \\
\hline F4 & 6.75 & 4 & 500 & $79.85 \pm 0.11$ & $262.3 \pm 1.58$ & $0.281 \pm 0.003$ \\
\hline F5 & 4.75 & 3 & 400 & $78.9 \pm 0.21$ & $263.4 \pm 0.84$ & $0.279 \pm 0.001$ \\
\hline F6 & 6.75 & 3 & 400 & $76.3 \pm 0.29$ & $257.9 \pm 0.85$ & $0.288 \pm 0.004$ \\
\hline F7 & 4.75 & 3 & 600 & $76.1 \pm 0.29$ & $260.2 \pm 1.13$ & $0.289 \pm 0.003$ \\
\hline F8 & 6.75 & 3 & 600 & $77.3 \pm 0.24$ & $264.5 \pm 0.57$ & $0.279 \pm 0.001$ \\
\hline F9 & 5.75 & 2 & 400 & $78.7 \pm 0.33$ & $257.5 \pm 0.57$ & $0.319 \pm 0.002$ \\
\hline F10 & 5.75 & 4 & 400 & $82.3 \pm 0.24$ & $260.3 \pm 0.82$ & $0.315 \pm 0.002$ \\
\hline F11 & 5.75 & 3 & 500 & $80.08 \pm 0.34$ & $259.1 \pm 1.16$ & $0.289 \pm 0.001$ \\
\hline F12 & 5.75 & 3 & 500 & $79.84 \pm 0.28$ & $260.1 \pm 0.65$ & $0.289 \pm 0.002$ \\
\hline $\mathrm{F} 13 *$ & 5.75 & 3 & 500 & $79.00 \pm 0.33$ & $257.1 \pm 1.76$ & $0.289 \pm 0.003$ \\
\hline
\end{tabular}

( ${ }^{*}$ Optimized formulation, $\mathrm{SD}=$ standard deviation, $\mathrm{n}=$ no. of times).

\subsection{UV-Spectrophotometer Analysis}

A standard stock solution of MJE was prepared by accurately dissolving $10 \mathrm{mg}$ of MJE in $10 \mathrm{~mL}$ of phosphate buffer at $\mathrm{pH}$ 7.4. The calibration curve of MJE was plotted within the concentration range of $5-60 \mu \mathrm{g} / \mathrm{mL}$, with a linearity equation of $\mathrm{Y}=0.0147 \mathrm{x}-0.0272$, and its $\mathrm{R}^{2}$ value 0.9954 at $285 \mathrm{~nm}$. The limit of detection (LOD) and limit of quantification (LOQ) values were 1.7 and $5 \mu \mathrm{g} / \mathrm{mL}$, respectively [4,19].

\subsection{Particle Size Analysis and Morphological Characterization}

\subsubsection{Particle Size and Polydispersity Index (PDI)}

The Zetasizer-1000 HS (Malvern Instruments, Malvern, UK) was used to study particle size and PDI. The particle size and PDI were measured with dynamic light scattering (DLS). Water was used to dilute the sample and then placed in a quartz cuvette and analyzed at a $90^{\circ}$ scattering angle. All of the batches were analyzed in triplicate, then mean and standard deviation (SD) value was calculated [31,32].

\subsubsection{Zeta Potential}

Zeta potential is an important parameter to predict the stability of the particulate formulation. The electric charge is reflected on the particle surface, which indicates the physical stability of the nanoparticle. It was measured by the Zetasizer-1000 HS (Malvern Instruments, Malvern, UK) [33].

\subsubsection{Structural Analysis by TEM}

Transmission Electron Microscopy (TEM Tecnai, G20, Philips Scientific, Amsterdam The Netherlands) was employed to study the shape of the developed nanoparticle. The sample was taken in the carbon-coated grid and stained with phosphotungstic acid under the microscope at 10-100 k times enlargements at $200 \mathrm{kV}$ voltage [34].

\subsubsection{Entrapment Efficiency}

The ultracentrifugation method was employed to determine the entrapment efficiency of MJE in the ZnO-MJE-NPs. The ZnO-MJE-NPs were centrifuged at $18,000 \mathrm{rpm}$ and $4{ }^{\circ} \mathrm{C}$ for $15 \mathrm{~min}$. The supernatants were collected and free MJE concentration was analyzed 
at $285 \mathrm{~nm}$ by a UV-spectrophotometer (Shimadzu-1601, New Delhi, India). The below mathematical formula was used to calculate the \% entrapment efficiency [35].

$$
\% \text { Entrapment efficiency }=\frac{\text { Total MJE }- \text { MJE in supernatant }}{\text { Total MJE }} \times 100
$$

\subsection{In Vitro Release Studies}

In vitro release of the $\mathrm{ZnO}-\mathrm{MJE}-\mathrm{NPs}$ and $\mathrm{MJE}$ dispersion was performed at $\mathrm{pH} 7.4$ using a dialysis membrane (molecular weight cut-off 10-12 KDa). Three milliliters of ZnO-MJE-NPs and MJE dispersion (15 mg of MJE) was filled into a dialysis bag and placed in $100 \mathrm{~mL}$ dissolution media of different $\mathrm{pH}$. The dissolution medium was stirred regularly at $100 \mathrm{rpm}$ and the temperature was maintained at $37^{\circ} \mathrm{C}$ on a magnetic stirrer. The drug content was measured by UV-spectrophotometer. A total of $2 \mathrm{~mL}$ of aliquots of the above solution was taken at a different time intervals (5, 10, $30 \mathrm{~min} ; 1,2,4,8,12$, and $24 \mathrm{~h}$ ) and was replaced with the same amount of dissolution medium to maintain the constant volume and concentration gradient [36,37]. The \% drug releases were calculated and plotted on the graph. The drug release data were fitted to different kinetic models such as zero order, first order, Higuchi, and Korsmeyer-Peppas to evaluate the release mechanisms from the $\mathrm{ZnO}-\mathrm{NPs}$ [38].

\subsection{Ex Vivo Studies}

A Franz diffusion apparatus ( $9 \mathrm{~mm}$ orifice diameter and receptor volume $5 \mathrm{~mL}$ ) was used to conduct the ex vivo permeation study using rat skin (IAEC/KSOP/E/20/03, Registration No 1099/PO/Re/S/CPCSEA). The stratum corneum with dermal layer in the downwards direction was placed in between the two compartments, i.e., donor and receptor. Tyrode solution $\mathrm{pH} 7.4$ was used as the permeation medium and filled into the receptor compartments [16]. A total of $1 \mathrm{~mL}$ (2 $\mathrm{mg}$ drug) of ZnO-MJE-NPs and MJE dispersion was poured into the donor cell, and temperature was maintained at $37 \pm 0.5^{\circ} \mathrm{C}$ throughout the study. At specific time intervals, $1 \mathrm{~mL}$ of released content was taken and analyzed by UV-spectrophotometer [39] at $285 \mathrm{~nm}$. The flux, permeability coefficient (PC), and enhancement ratio (ER) were calculated.

$$
\begin{gathered}
\text { Permeability coefficient }=\frac{\text { Flux }}{\text { Area } \times \text { total amount of MJE }} \\
\mathrm{ER}=\frac{\text { PC of formualtion }}{\text { PC of pure drug }}
\end{gathered}
$$

\subsection{Antimicrobial Study}

The antimicrobial activity of the prepared $\mathrm{ZnO}-\mathrm{MJE}-\mathrm{NPs}$ was evaluated against the tested organisms (S. Aureus, and E. Coli) using the pour plate method. The study was performed in the sterilized agar medium. The test samples were dispersed in sterilized water [40]. The prepared melted sterilized nutrient agar medium was transferred and mixed with the microorganism in Petri plates and allowed to stand for solidification without any agitation. The well $(10 \mathrm{~mm})$ was made using a sterilized borer, and $1 \mathrm{~mL}$ of varied concentrations of the drug (20-320 $\mu \mathrm{g} / \mathrm{mL}$ of MJE) was added. The Petri plates were set aside for a few hours and then placed into an incubator for $24 \mathrm{~h}$. The study was conducted in triplicate and ZOI was noted using a graduated scale in millimeters (mm).

\subsection{Antioxidant Activity}

The percentage of antioxidant activity (\% AA) of ZnO-MJE-NPs and MJE dispersion was assessed by 2, 2-Diphenyl-1-picrylhydrazyl (DPPH) free radical scavenging method as described by Brand-Williams et al. [41]. The 0.02\% DPPH solution was prepared in ethanol. ZnO-MJE-NPs and MJE dispersion at 10-100 $\mu \mathrm{g} / \mathrm{mL}$ from the stock solution $(1 \mathrm{mg} / \mathrm{mL})$. A total of $500 \mu \mathrm{L}$ of each concentration of ZnO-MJE-NPs and MJE dispersion was added 
into the DPPH solution $(125 \mu \mathrm{L})$ and let stand for $1 \mathrm{~h}$ in a dark place. The change in color from violet to colorless indicated antioxidant activity. The absorbance (Abs) was read at 517 nm using a UV-VIS spectrophotometer (DU 800; Beckman Coulter, Fullerton, CA, USA). A DPPH solution without ZnO-MJE-NPs and MJE dispersion was taken as blank. The \% AA was calculated by the below equation.

$$
\% \mathrm{AA}=\frac{\text { Absorbence of control sample }- \text { Absorbance of test sample }}{\text { Absorbence ofcontrol sample }} \times 100
$$

\subsection{Stability Studies}

A stability study was performed to assess the change in formulation during storage or shelf life. The optimized ZnO-MJE-NP formulation was sealed in glass vials and placed into a stability chamber at $25 \pm 1{ }^{\circ} \mathrm{C} / 60 \% \mathrm{RH}$ for 3 months. Samples were taken at 0 , 1,2 , and 3 months and were evaluated for their physical appearance, particle size, and entrapment efficiency [42].

\subsection{Statistical Analysis}

All the data were expressed in mean \pm SD. The Graph Pad prism software was used for statistical analysis. Student's $t$ test was used to assess statistical significance at $p \leq 0.005$ for all the parameters. A statistical significance at $p<0.001$ was used to assess antimicrobial activity.

\section{Results and Discussion}

\subsection{Optimization}

\subsubsection{Effect of independent variables on particle size}

The polynomial equation for particle size is given below.

Particle Size $=+259.38-0.15 \mathrm{~A}-0.90 \mathrm{~B}-0.52 \mathrm{C}+0.50 \mathrm{AB}+2.45 \mathrm{AC}-2.30 \mathrm{BC}+2.62 \mathrm{~A}^{2}+0.62 \mathrm{~B}^{2}-0.41 \mathrm{C}^{2}$

The results of independent variables on the particle sizes of different formulations are given in Table 1. Negative and positive signs indicate the favoring and un-favoring of the independent variable over the response. This equation showed $\mathrm{B}, \mathrm{AC}, \mathrm{BC}, \mathrm{A}^{2}$ to be significant model terms because $p<0.05$. The model F-value of $23.30(p<0.05)$ indicated that the model was significant. The quadratic model was evaluated based on an ANOVA and indicated that it was significantly fitted (Table 2). The F-value of lack of fit of 0.49 indicated that it was non-significant, which was good for the model. The $\mathrm{R}^{2}$ of the quadratic model was 0.9859 , which was greater than the other models. The adequate precession greater than 4 (14.72) indicated an adequate signal. The $\mathrm{ZnSO}_{4}$ showed the positive effect on particle size. An increase in the concentration of $\mathrm{ZnSO}_{4}$ resulted in increased particle size because of an increase in the viscosity of the dispersion. The sonication time (B) exhibited a negative effect on particle size. The size of the nanoparticle decreased with increasing sonication time because of the breaking of particles. The stirring speed (C) exhibited a negative effect on the particle size, which meant that with increased stirring speed the particle size decreased from the breaking of the particle, but this was not affected significantly. Graphs of the 3D, contour, and actual and predicted values of the particle size are shown in Figure 2A-C.

\subsubsection{Effect of Independent Variables on Polydispersity Index (PDI)}

The effects of independent variables on the PDI of different formulations is given in Table 1. The experimental design showed that the quadratic model was found to be the best fitted model. The F-value of 10.50 indicated that the model was significantly fitted. The lack of fit F-value of 0.71 implied the lack of fit was not significant relative to the pure error. There was $48.84 \%$ chance that a lack of fit F-value of 0.71 could occur because of noise. Non-significant lack of fit was good. The $\mathrm{R}^{2}$ of 0.9692 was greater than other models (linear, second order), indicating that model was well fitted. The adequate precession of 
10.74 ( $>4$ ) revealed that model was significantly fitted. An ANOVA of the quadratic model was calculated and is given in Table 2. Graphs of the 3D, contour, and actual and predicted values of particle size are displayed in Figure $3 \mathrm{~A}, \mathrm{~B}$, showing the effect of the independent variables on the PDI. The actual and predicted values of the PDI expressed in Figure 3C indicated the closeness of both values.

Table 2. ANOVA of responses (particle size, PDI, and entrapment efficiency).

\begin{tabular}{|c|c|c|c|c|c|c|}
\hline \multirow[b]{2}{*}{ Source } & \multicolumn{6}{|c|}{ Particle Size } \\
\hline & Sum of Square & DF & Mean Square & F-Value & $p$-Value & \\
\hline Model & 64.30 & 9 & 7.14 & 23.30 & 0.0126 & Significant \\
\hline $\mathrm{A}-\mathrm{ZnSO}_{4} \cdot 7 \mathrm{H}_{2} \mathrm{O}$ & 0.1800 & 1 & 0.1800 & 0.5870 & 0.4994 & - \\
\hline B-Ultra-Sonication Time & 3.24 & 1 & 3.24 & 10.57 & 0.0475 & - \\
\hline C-Stirring Speed & 2.89 & 1 & 2.89 & 9.42 & 0.0546 & - \\
\hline $\mathrm{AB}$ & 1.00 & 1 & 1.00 & 3.26 & 0.1687 & - \\
\hline $\mathrm{AC}$ & 24.01 & 1 & 24.01 & 78.29 & 0.0030 & - \\
\hline $\mathrm{BC}$ & 7.05 & 1 & 7.05 & 23.00 & 0.0172 & - \\
\hline $\mathrm{A}^{2}$ & 16.11 & 1 & 16.11 & 52.52 & 0.0054 & - \\
\hline $\mathrm{B}^{2}$ & 1.52 & 1 & 1.52 & 4.95 & 0.1126 & - \\
\hline$C^{2}$ & 0.4563 & 1 & 0.4563 & 1.49 & 0.3097 & - \\
\hline Residual & 0.9200 & 3 & 0.3067 & - & & - \\
\hline Lack of Fit & 0.1800 & 1 & 0.1800 & 0.4865 & 0.5577 & Not Significant \\
\hline Pure Error & 0.7400 & 2 & 0.3216 & - & - & - \\
\hline \multirow[t]{2}{*}{ Cor Total } & 65.22 & 12 & - & - & - & - \\
\hline & & \multicolumn{5}{|c|}{ PDI } \\
\hline Model & 0.0018 & 9 & 0.0002 & 10.50 & 0.0393 & Significant \\
\hline $\mathrm{A}-\mathrm{ZnSO}_{4} \cdot 7 \mathrm{H}_{2} \mathrm{O}$ & 0.0000 & 1 & 0.0000 & 1.10 & 0.3719 & - \\
\hline B-Ultra-sonication time & 0.0000 & 1 & 0.0000 & 0.8306 & 0.4293 & - \\
\hline C-Stirring speed & $2.500 \times 10^{7}$ & 1 & $2.500 \times 10^{7}$ & 0.0130 & 0.9165 & - \\
\hline $\mathrm{AB}$ & 0.0000 & 1 & 0.0000 & 2.54 & 0.2090 & - \\
\hline $\mathrm{AC}$ & 0.0001 & 1 & 0.0001 & 4.68 & 0.1191 & - \\
\hline $\mathrm{BC}$ & $2.168 \times 10^{19}$ & 1 & $2.168 \times 10^{19}$ & $1.126 \times 10^{14}$ & 1.0000 & - \\
\hline$A^{2}$ & 0.0006 & 1 & 0.0006 & 30.17 & 0.0119 & - \\
\hline $\mathrm{B}^{2}$ & 0.0008 & 1 & 0.0008 & 44.08 & 0.0070 & - \\
\hline$C^{2}$ & 0.0004 & 1 & 0.0004 & 20.77 & 0.0198 & - \\
\hline Residual & 0.0001 & 3 & 0.0000 & - & - & - \\
\hline \multirow[t]{3}{*}{ Lack of Fit } & 0.0000 & 1 & 0.0000 & 0.7090 & 0.4884 & Not significant \\
\hline & 0.0000 & 2 & - & - & - & - \\
\hline & 0.0019 & 12 & - & - & - & - \\
\hline
\end{tabular}


Table 2. Cont.

\begin{tabular}{|c|c|c|c|c|c|c|}
\hline \multirow[b]{2}{*}{ Source } & \multicolumn{6}{|c|}{ Particle Size } \\
\hline & Sum of Square & DF & Mean Square & F-Value & $p$-Value & \\
\hline & & \multicolumn{5}{|c|}{ Entrapment efficiency } \\
\hline Model & 58.83 & 9 & 6.54 & 26.34 & 0.0106 & Significant \\
\hline $\mathrm{A}-\mathrm{ZnSO} \mathrm{O}_{4} \cdot 7 \mathrm{H}_{2} \mathrm{O}$ & 1.71 & 1 & 1.71 & 6.90 & 0.0786 & - \\
\hline B-Ultra-sonication time & 0.3600 & 1 & 0.3600 & 1.45 & 0.3148 & - \\
\hline C-Stirring speed & 0.8100 & 1 & 0.8100 & 3.26 & 0.1685 & - \\
\hline $\mathrm{AB}$ & 3.42 & 1 & 3.42 & 13.79 & 0.0340 & - \\
\hline $\mathrm{AC}$ & 3.61 & 1 & 3.61 & 14.55 & 0.0317 & - \\
\hline $\mathrm{BC}$ & 5.88 & 1 & 5.88 & 23.70 & 0.0166 & - \\
\hline $\mathrm{A}^{2}$ & 0.5003 & 1 & 0.5003 & 2.02 & 0.2507 & - \\
\hline $\mathrm{B}^{2}$ & 15.23 & 1 & 15.23 & 61.36 & 0.0043 & - \\
\hline$C^{2}$ & 10.57 & 1 & 10.57 & 42.58 & 0.0073 & - \\
\hline Residual & 0.7445 & 3 & 0.2482 & - & - & - \\
\hline Lack of Fit & 0.1013 & 1 & 0.1013 & 0.3148 & 0.6312 & not significant \\
\hline Pure Error & 0.6432 & 2 & - & - & - & - \\
\hline Cor Total & 59.58 & 12 & - & - & - & - \\
\hline
\end{tabular}

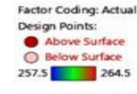

$x_{1}=A$ Ansos-7H2O
$x_{2}=\mathrm{B}:$ Utrasonication time Actual frector
cistiring speed $=500$
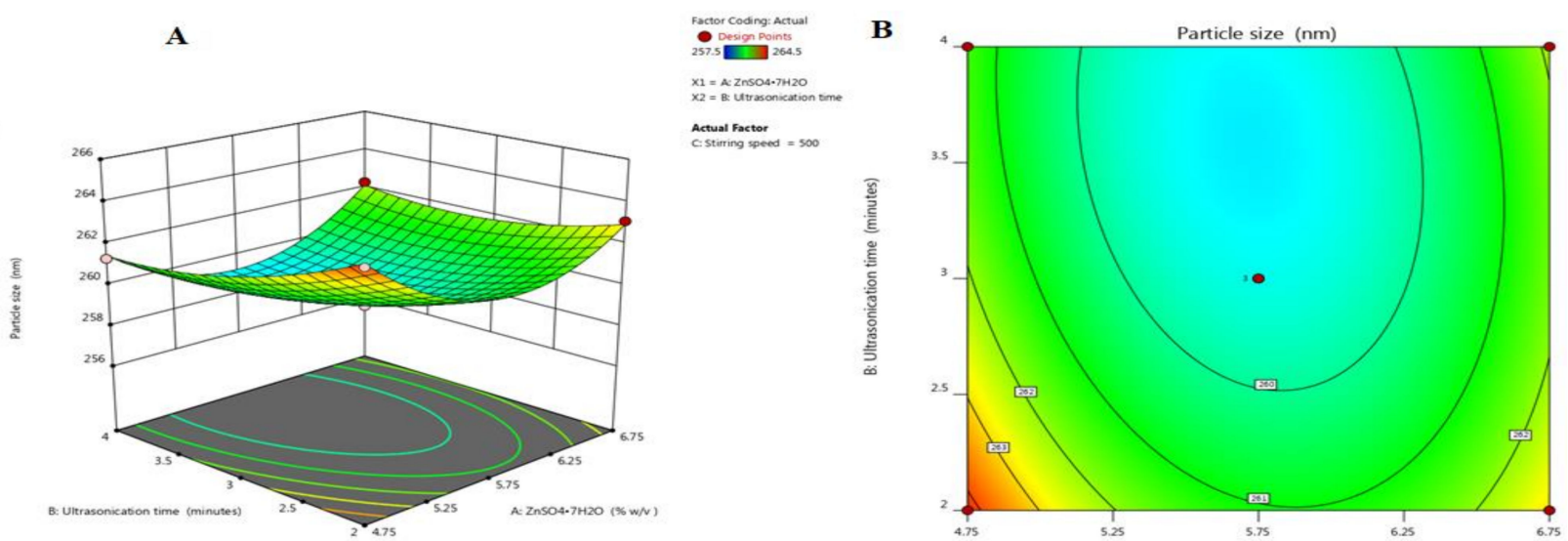

C

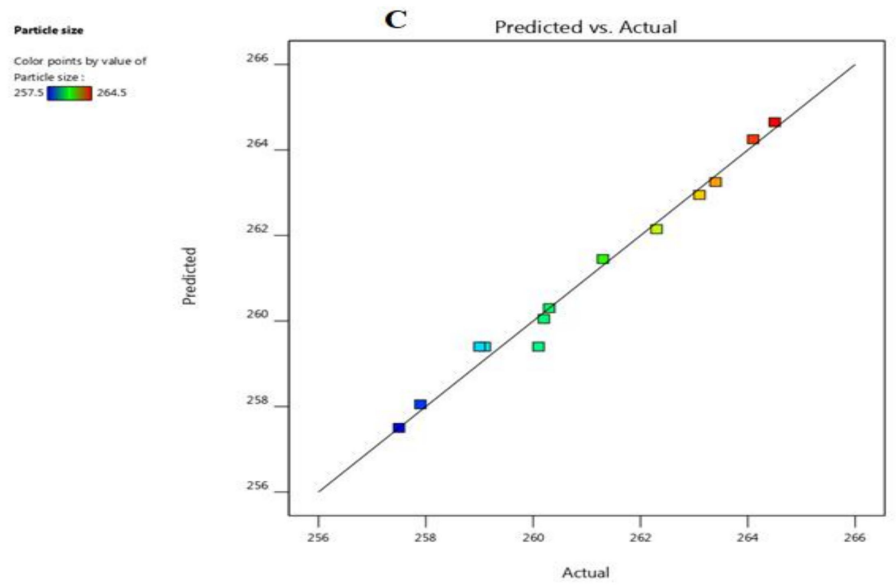

A: ZnSO4.7H2O (\% w/v)

Figure 2. 3D (A), contour (B), and actual and predicted (C) values of particle size. 


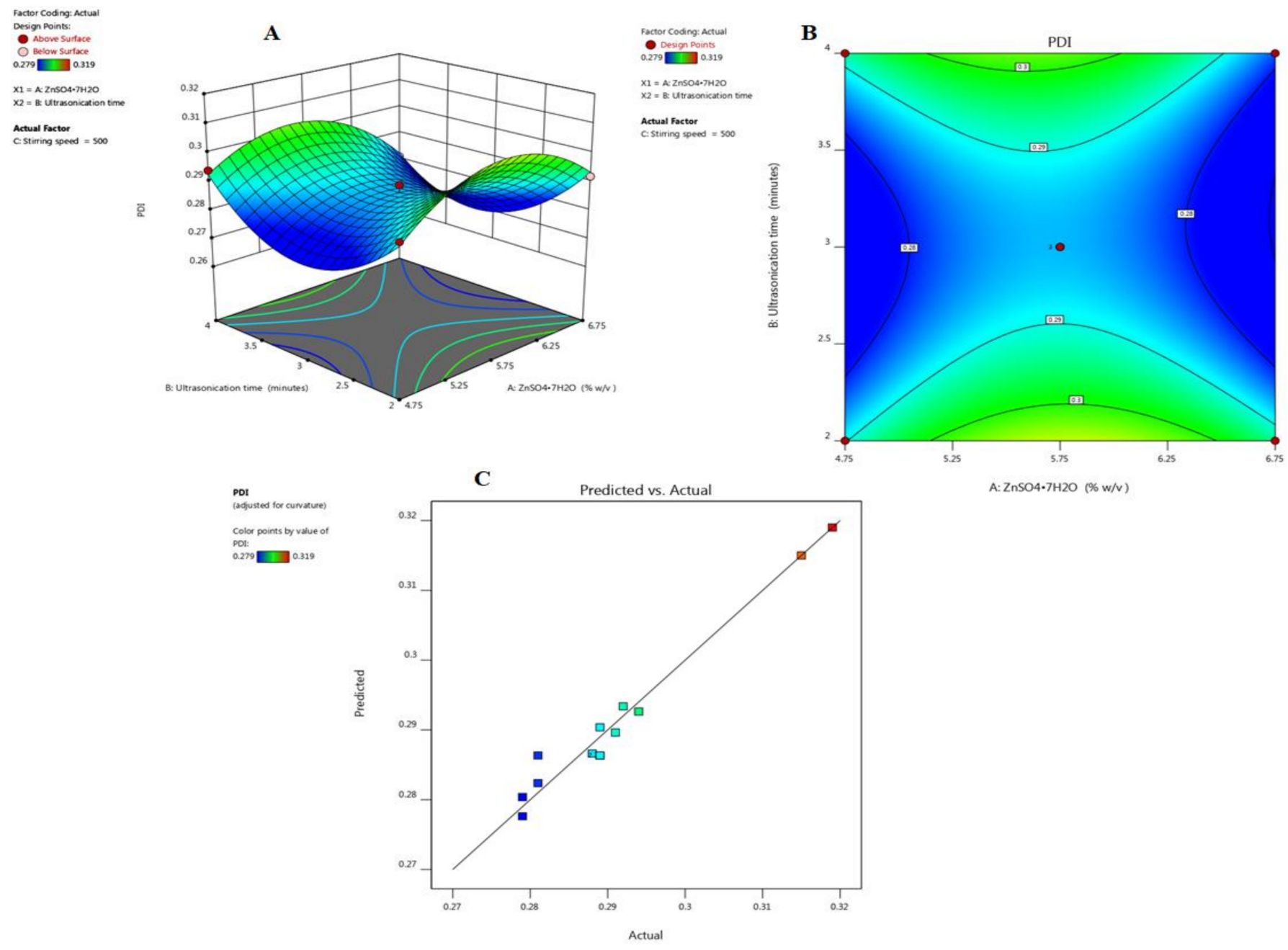

Figure 3. 3D (A), contour (B), and actual and predicted (C) values of particle size.

\subsubsection{Effect of Independent Variables on Entrapment Efficiency}

The entrapment efficiency of all the batches was determined in a triplicate manner and the results are summarized in Table 1. The effect of formulation variables was studied on entrapment efficiency. The ANOVA suggested the quadratic model, and F-value of 26.3 $(p<0.0500)$ implied the model was significant. The F-value of 0.31 implied that the lack of fit was not significant relative to the pure error. Non-significant lack of fit was desired; we wanted the model to fit (Table 2). The following coded equation describes the relation between independent factors and entrapment efficiency.

Entrapment efficiency $=+94.99+0.4625 \mathrm{~A}-0.30 \mathrm{~B}-0.21 \mathrm{C}-0.93 \mathrm{AB}+0.95 \mathrm{AC}-2.10 \mathrm{BC}-0.85 \mathrm{~A}^{2}+2.52 \mathrm{~B}^{2}-1.47 \mathrm{C}^{2}$

The equation showed in this case that $\mathrm{AB}, \mathrm{AC}, \mathrm{BC}, \mathrm{B}^{2}$, and $\mathrm{C}^{2}$ are significant model terms. It indicated that Factor $A$ had a positive effect, and $B$ and $C$ had a negative effect on entrapment efficiency. Interaction terms $(A B, B C)$ showed a positive effect, and $A C$ had a negative effect on entrapment efficiency. However, higher-order terms $\left(\mathrm{A}^{2}\right.$ and $C^{2}$ ) showed a negative effect, and $B^{2}$ had a positive effect on entrapment efficiency. The effect of independent variables on the entrapment efficiency is graphically expressed in the 3-D and contour plot in Figure 4A,B. The plots indicate that, by increasing the concentration of $\mathrm{ZnSO}_{4} \cdot 7 \mathrm{H}_{2} \mathrm{O}$, entrapment efficiency increased, whereas when increasing the ultra-sonication time and stirring speed, the entrapment efficiency decreased because leaching of the drug takes place during the breaking of particles. 


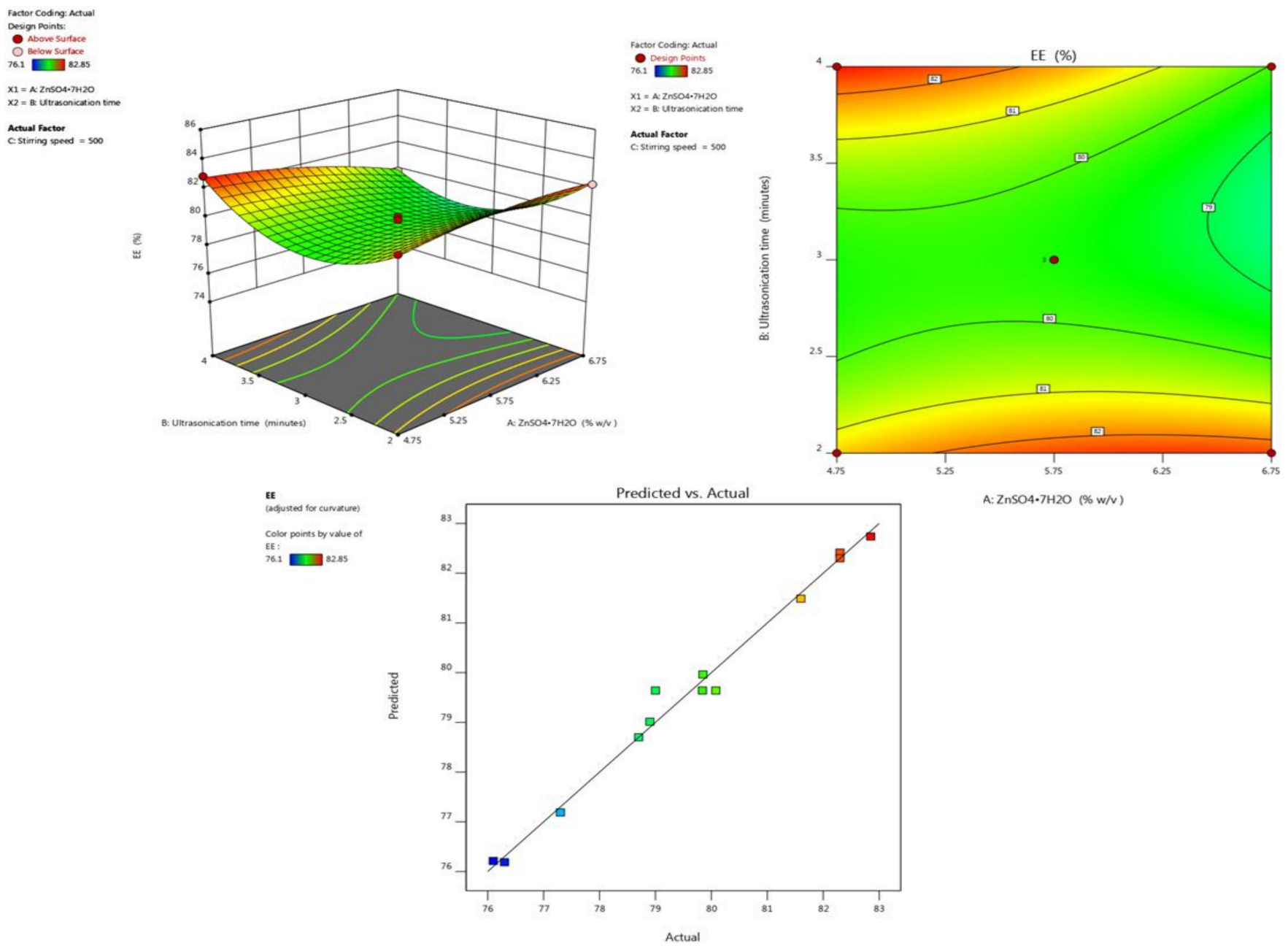

Figure 4. 3D (A), contour (B), and actual and predicted (C) values of particle size.

\subsubsection{Selection of Optimized Formulation}

The optimized formulation was chosen from the point prediction of the software, which explained the center point of the formulation. The composition of the optimized formulation had $5.75 \% w / v$ of $\mathrm{ZnSO}_{4} \cdot 7 \mathrm{H}_{2} \mathrm{O}$, at 3.00 min ultrasonic time and $500 \mathrm{rpm}$ stirring speed. The predicted value was $79.731 \% \mathrm{EE}, 259.38 \mathrm{~nm}$ particle size, and 0.280 PDI. The experimental value of the optimized formulation was found to be $257.1 \pm 1.76$ particle size, $79.00 \pm 0.33 \%$ entrapment, and $0.289 \pm 0.003$ efficiency. The actual value showed less deviation from the predicted value.

\subsection{Particle Size, Zeta Potential and PDI}

The particle size, zeta potential, and PDI of ZnO-MJE-NPs were found to be $257.1 \pm 1.76 \mathrm{~nm}$, $-22.7 \mathrm{mV}$, and $0.289 \pm 0.003$, respectively (Figure 5). The PDI value of $<0.5$ indicated homogeneous distribution and uniform particle sizes. The zeta potential of $-22.7 \mathrm{mV}$ indicated that the particle was in disaggregated form and stable.

\subsection{Morphological Examination}

The morphology of ZnO-MJE-NPs was analyzed by TEM and showed that the nanoparticles were spherical in shape, with uniform size and disaggregated form (Figure 5). 


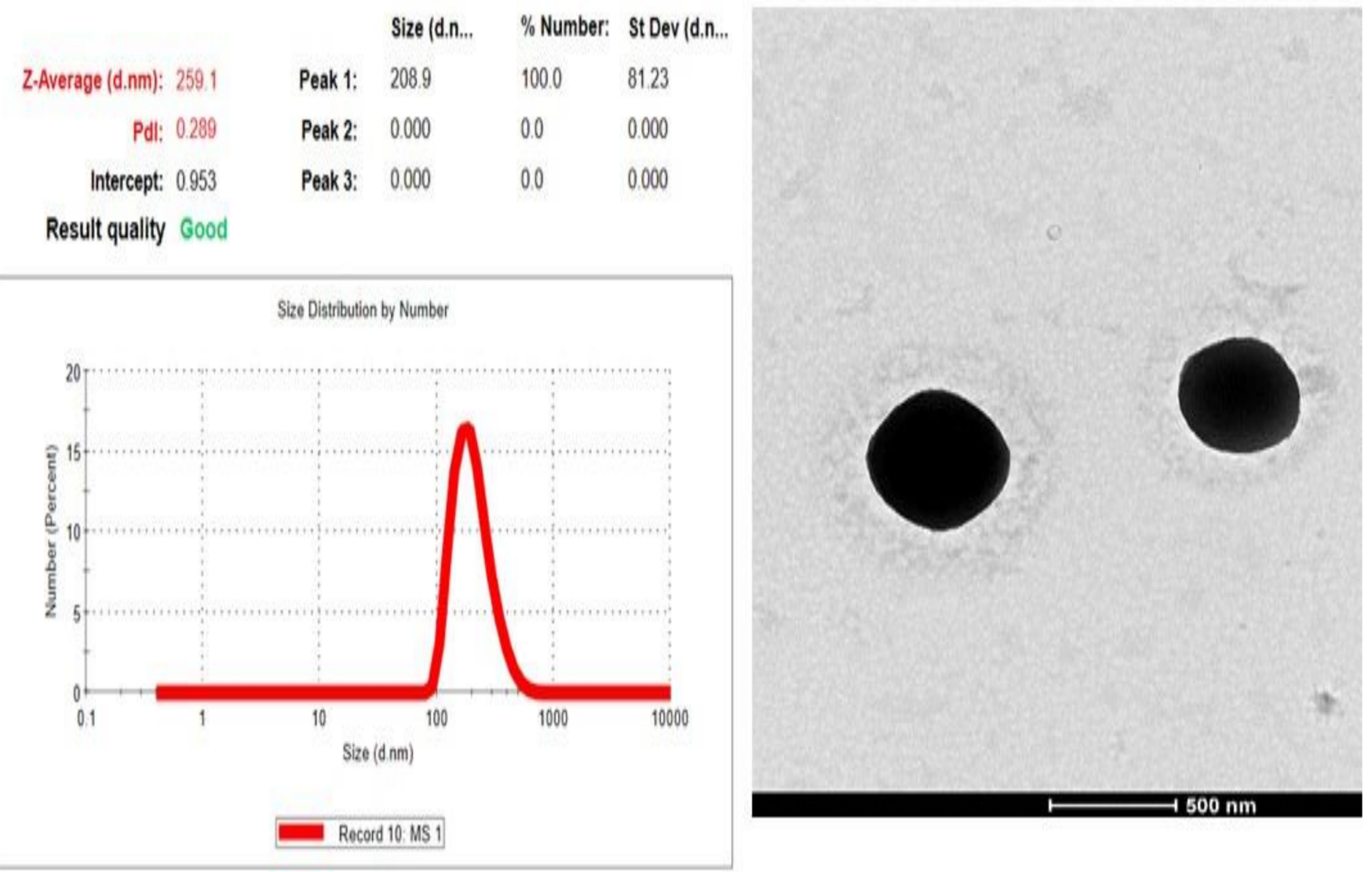

Figure 5. Particle size, zeta potential, and PDI value and morphological examination.

\subsection{In Vitro Release Studies}

Figure 6 depicts the release of MJE from ZnO-MJE-NPs-opt at $\mathrm{pH} 7.4$ and compares it with the MJE dispersion. The ZnO-MJE-NPs-opt dispersion and MJE dispersion exhibited $34.5 \pm 0.25 \%$ and $13.11 \pm 2.32 \%$ MJE release, respectively, at $\mathrm{pH} 7.4$. Data obtained by the in vitro drug release of $\mathrm{ZnO}-\mathrm{MJE}-\mathrm{NPs}$-opt were fitted to various drug release kinetic models such as the zero order model, first order model, Higuchi model, and KorsmeyerPeppas model. The correlation coefficient $\left(\mathrm{R}^{2}\right)$ was calculated and is shown in Table 3 . The maximum $\mathrm{R}^{2}$ value indicated the Korsmeyer-Peppas model was considered as a best-fit model. The value of " $\mathrm{n}$ " was found to be 0.273 (pH 7.4), which indicated that drug release from the optimized formulation followed quasi-Fickian diffusion, i.e., non-swellable matrix diffusion [38].

Table 3. Various kinetic release models.

\begin{tabular}{ccccccccc}
\hline $\begin{array}{c}\text { Dissolution } \\
\text { Media }\end{array}$ & \multicolumn{2}{c}{ Zero Order } & \multicolumn{2}{c}{ First Order } & \multicolumn{2}{c}{ Higuchi Model } & \multicolumn{2}{c}{ Korsmeyer-Peppas } \\
\hline- & $\mathrm{R}^{2}$ & $\mathrm{~K}$ & $\mathrm{R}^{2}$ & $\mathrm{~K}$ & $\mathrm{R}^{2}$ & $\mathrm{~K}$ & $\mathrm{R}^{2}$ & $\mathrm{~K}$ \\
\hline $\mathrm{pH} 7.4$ & 0.8725 & 0.033 & 0.9098 & 0.000 & 0.9679 & 1.143 & 0.9912 & 4.982 \\
\hline
\end{tabular}

\subsection{Ex Vivo Studies}

The permeation study of the ZnO-MJE-NPs-opt and MJE dispersion was done on rat skin for $6 \mathrm{~h}$ and data are shown in Figure 7. The percentages of cumulative drug permeated across the rat skin were found to be 24 and $63.26 \%$ for the MJE dispersion and ZnO-MJE-NPs-opt, respectively. The PC values of the ZnO-MJE-NPs-opt and MJE dispersion were found to be $1.97 \times 10^{-1}$ and $5.497 \times 10^{-2}$, respectively. The ER of $\mathrm{ZnO}$ MJE-NPs-opt was 3.60-fold higher than the MJE dispersion. Thus, it can be assumed that 
the MJE nanoparticles helped to increase the permeation across the skin, and hence, a better therapeutic response can be expected as compared to the MJE dispersion [43].

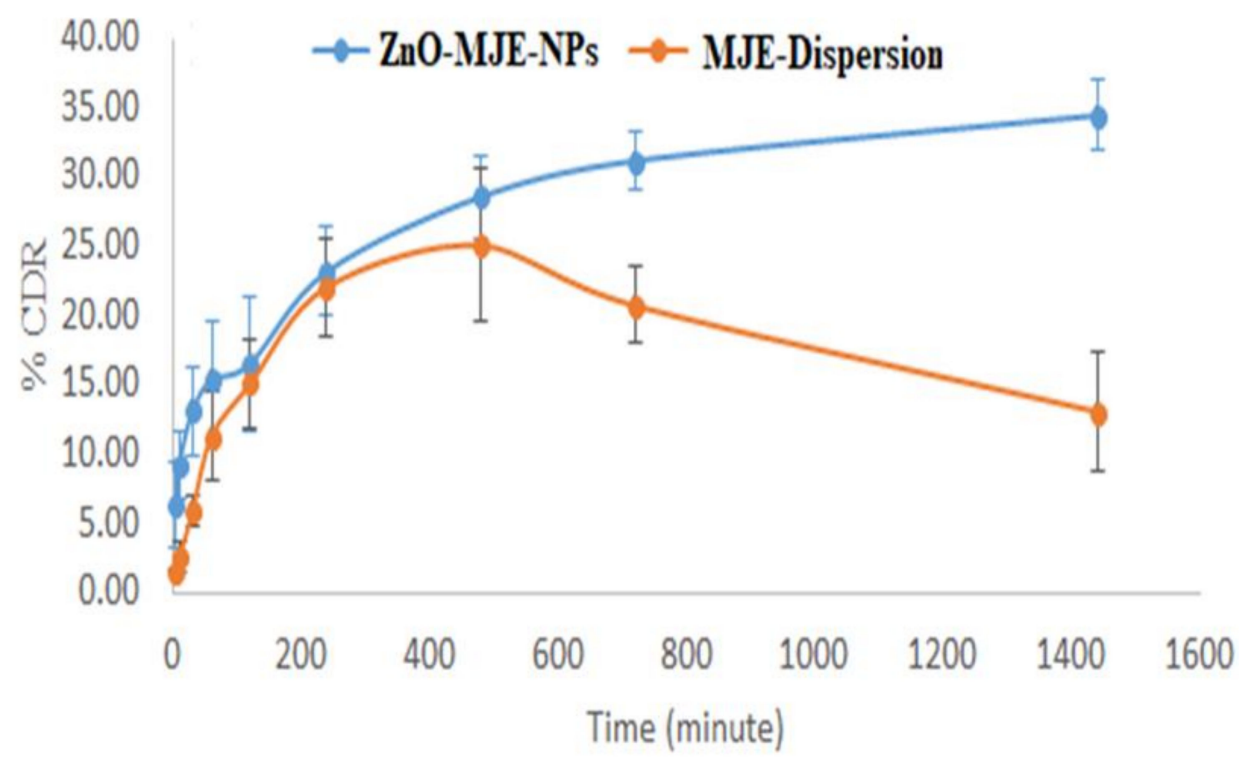

Figure 6. Comparative releases of the drug at $\mathrm{pH} 7.4$.

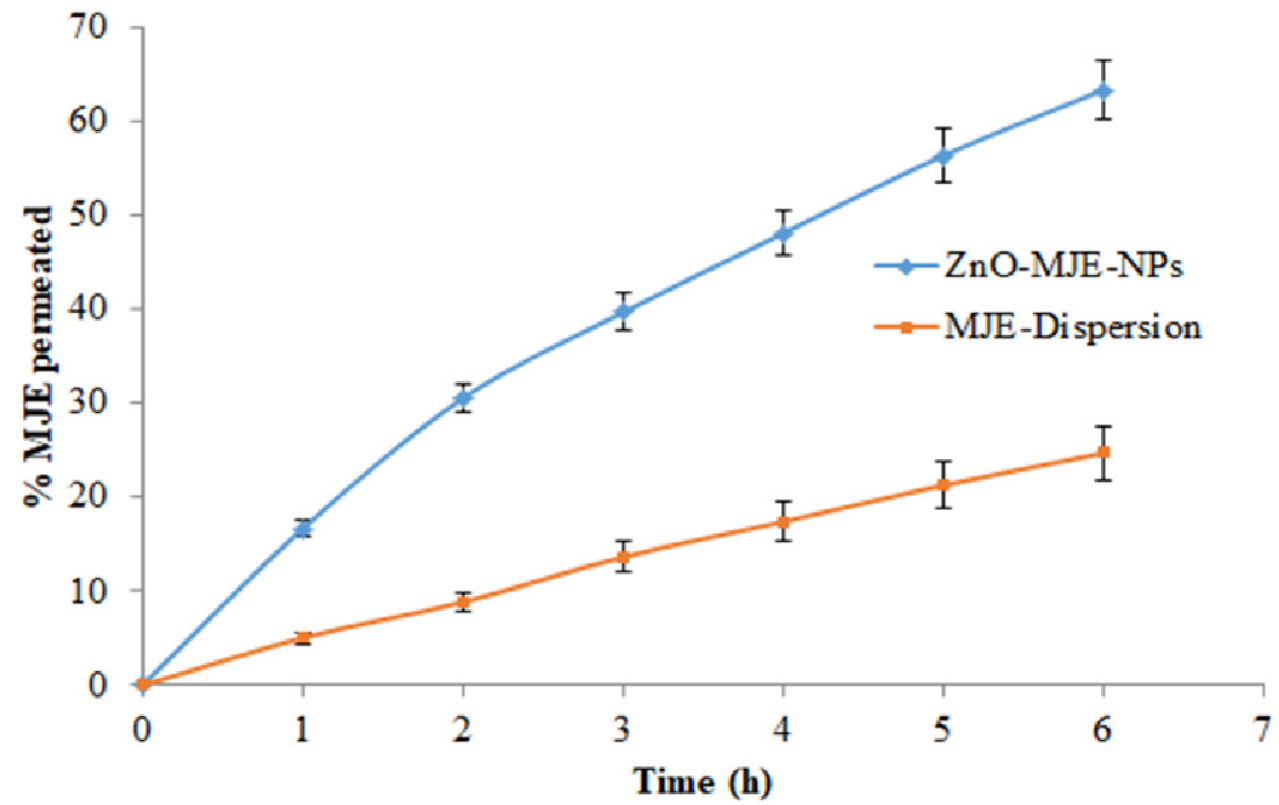

Figure 7. Comparative permeation of $\mathrm{ZnO}$ nanosuspension and MJE suspension.

\subsection{Antimicrobial Study}

The antimicrobial activity of ZnO-MJE-NPs and MJE was evaluated on S. Aureus and E. Coli. The ZOI values of ZnO-MJE-NPs were found to be $14 \pm 2$ and $18 \pm 1 \mathrm{~mm}$ against S. Aureus and E. Coli, respectively, at $24 \mathrm{~h}$. The pure MJE showed a ZOI of $9 \pm 1 \mathrm{~mm}$ against $S$. Aureus and $12 \pm 2 \mathrm{~mm}$ against $E$. Coli at $24 \mathrm{~h}$. The significantly $(p<0.05)$ high efficacy of ZnO-MJE-NPs was due to the higher solubility, nanosize, as well as penetration in cells of the microorganism than pure MJE. The difference in the activity was due to the permeability barrier provided by the presence of the cell wall $[44,45]$. The blend of MJE and $\mathrm{ZnO}$ had a synergistic effect on antibacterial activity. 


\subsection{Antioxidant Activity}

The antioxidant activity of the prepared ZnO-MJE-NPs was evaluated and compared with the MJE extract, and data are shown in Figure 8. It was observed that by increasing the concentration of MJE, the antioxidant activity increased. Significantly $(p<0.05)$ higher antioxidant activity was found in the optimized ZnO-MJE-NPs than in the pure MJE dispersion. The antioxidant activity of ZnO-MJE-NPs was shown to be highest $(93.14 \pm 4.05 \%)$ at $100 \mu \mathrm{g} / \mathrm{mL}$ concentrations; however, the MJE dispersion showed $60.31 \pm 6.05 \%$ at $100 \mu \mathrm{g} / \mathrm{mL}$. The significantly $(p<0.05)$ high activity of MJE in ZnO-MJE-NPs was due to the high solubility of MJE. MJE has antioxidant and robust scavengers of free radicals [46]. The antioxidant activity was enhanced by the increased solubility of MJE in ZnO-MJE-NPs.

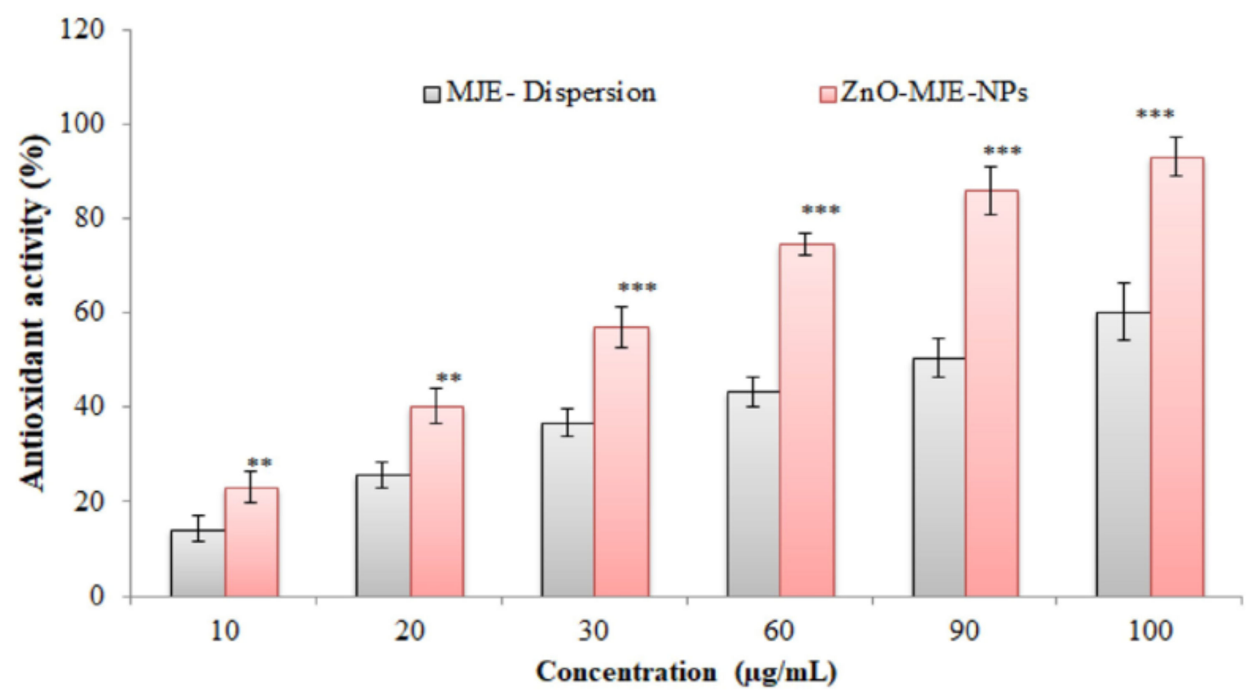

Figure 8. Antioxidant activity of MJE dispersion and ZnO-MJE-NPs. ${ }^{* *} p<0.001,{ }^{* * *} p<0.0001$.

\subsection{Stability Studies}

Stability of nanoformulation is an important requirement for the shelf life of the formulation. The parameters of the stability study of MJE nanoparticles are given in Table 4, and they were within limits, which indicated that nanoformulation was stable for 3 months.

Table 4. Result of the stability study of ZnO-MJE-NPs at $25 \pm 1{ }^{\circ} \mathrm{C} / 60 \% \mathrm{RH}$ for 3 months.

\begin{tabular}{|c|c|c|c|c|}
\hline \multirow[t]{2}{*}{ Months } & \multicolumn{4}{|c|}{ Evaluation Parameter } \\
\hline & Physical Appearance & $\begin{array}{c}\text { Particle Size } \\
(\text { Mean } \pm \text { SD) } \\
(\mathbf{N}=3)\end{array}$ & $\begin{array}{c}\text { Entrapment Efficiency } \\
(\text { Mean } \pm \text { SD) } \\
(\mathrm{N}=3)\end{array}$ & $\begin{array}{c}\text { Drug Content } \\
(\text { Mean } \pm \mathrm{SD}) \\
(\mathrm{N}=3)\end{array}$ \\
\hline 0 & $\begin{array}{c}\text { Clear and No } \\
\text { Sedimentation or Cake } \\
\text { Formation. }\end{array}$ & $262.5 \pm 2.36$ & $78.78 \pm 2.51$ & $97.26 \pm 2.17$ \\
\hline 1 & $\begin{array}{c}\text { Clear and No } \\
\text { Sedimentation or Cake } \\
\text { Formation. }\end{array}$ & $265.1 \pm 4.17$ & $77.89 \pm 1.98$ & $98.56 \pm 1.88$ \\
\hline 2 & $\begin{array}{c}\text { Clear and No } \\
\text { Sedimentation or Cake } \\
\text { Formation. }\end{array}$ & $263.7 \pm 3.11$ & $76.82 \pm 2.28$ & $97.76 \pm 2.51$ \\
\hline 3 & $\begin{array}{c}\text { Clear and No } \\
\text { Sedimentation or Cake } \\
\text { Formation. }\end{array}$ & $267.5 \pm 2.78$ & $76.23 \pm 2.76$ & $97.35 \pm 2.51$ \\
\hline
\end{tabular}




\section{Discussion}

Green synthesis of ZnO-NPs and Ag-NPs has previously been reported for Rubia cordifolia. In this study, the preparation method for the nanoparticles was modified, which helped in achieving a better drug release. A new approach to optimization of the formulation method using BBD lessened the laboratory work with an efficient result. A study carried out for the type of response surface using Box-Behnken design, where a quadratic model was followed, indicated that the result of the optimization of the formulation was good when compared to previous studies. The stability studies of the formulation explained the shelf life of the drug. In vitro and ex vivo comparative drug release studies in the present research indicated that the therapeutic effects of transdermal delivery are good. The nanosize of the particles enhanced their permeability and solubility, which increased the therapeutic effects. This was confirmed by the antimicrobial and anti-oxidant activity.

The overall result of this research will be helpful for further research based on different dosage forms as well as pharmacological activities.

\section{Conclusions}

It was concluded that the Design-Expert software assisted in the development and optimization of the $\mathrm{ZnO}$ nanoparticles $\mathrm{MJE}$ formulation. The in vitro release results showed that the $\mathrm{ZnO}$ nanoparticle formulation has a better release profile. The optimized formulation's skin permeation and stability study results indicated that this nanoformulation has better therapeutic effects. The $\mathrm{ZnO}$ nanoparticles showed better in vitro release, antimicrobial and antioxidant activities, and this optimized formulation may have high therapeutic value.

Author Contributions: Conceptualization, M.T.; methodology J.K., A.S. and M.T.; software, A.Z. and V.K. validation, M.K.A. and S.J.G.; formal analysis, C.K.; investigation, B.P.P.; resources, A.A.; data curation J.K. and A.Z.; writing—original draft preparation M.T. All authors have read and agreed to the published version of the manuscript.

Funding: No external funded for research.

Institutional Review Board Statement: Not applicable.

Informed Consent Statement: Not applicable.

Data Availability Statement: The data presented in this work are available in the article.

Acknowledgments: Authors are thankful to the Taif University Researchers Supporting Project (TURSP-2020/124) Taif University, Taif, Saudi Arabia.

Conflicts of Interest: The authors report no conflict of interest.

Sample Availability: Samples are not available from the author.

\section{References}

1. Peterson, C.T.; Pourang, A.; Dhaliwal, S.; Kohn, J.N.; Uchitel, S.; Singh, H.; Mills, P.J.; Peterson, S.N.; Sivamani, R.K. Modulatory Effects of Triphala and Manjistha Dietary Supplementation on Human Gut Microbiota: A Double-Blind, Randomized, PlaceboControlled Pilot Study. J. Altern. Complement. Med. 2020, 26, 1015-1024. [CrossRef]

2. Shan, M.; Yu, S.; Yan, H.; Chen, P.; Zhang, L.; Ding, A. A Review of the Botany, Phytochemistry, Pharmacology and Toxicology of Rubiae Radix et Rhizoma. Molecules 2016, 21, 1747. [CrossRef] [PubMed]

3. Shilpa, P.N.; Venkatabalasubramanian, S.; Devaraj, S.N. Ameliorative effect of methanol extract of Rubia cordifoliain Nnitrosodiethylamine-induced hepatocellular carcinoma. Pharm. Biol. 2012, 50, 376-383. [CrossRef] [PubMed]

4. Chandrashekar, B.S.; Prabhakara, S.; Mohan, T.; Shabeer, D.; Bhandare, B.; Nalini, M.; Sharmila, P.S.; Meghana, D.L.; Reddy, B.K.; Rao, H.H.; et al. Characterization of Rubia cordifolia L. root extract and its evaluation of cardioprotective effect in Wistar rat model. Indian J. Pharmacol. 2018, 50, 12-21. [PubMed]

5. Cai, Y.; Sun, M.; Xing, J.; Corke, H. Antioxidant phenolic constituents in roots of Rheum officinale and Rubia cordifolia: Structureradical scavenging activity relationships. J. Agric. Food Chem. 2004, 52, 7884-7890. [CrossRef]

6. Shen, C.H.; Liu, C.T.; Song, X.J.; Zeng, W.Y.; Lu, X.Y.; Zheng, Z.L.; Pan, J.; Zhan, R.T.; Yan, P. Evaluation of analgesic and anti-inflammatory activities of Rubia cordifolia L. by spectrum-effect relationships. J. Chromatogr. B 2018, 1090, 73-80. [CrossRef] 
7. Bonifácio, B.V.; da Silva, P.B.; dos Santos Ramos, M.A.; Negri, K.M.S.; Bauab, T.M.; Chorilli, M. Nanotechnology-based drug delivery systems and herbal medicines: A review. Int. J. Nanomed. 2014, 9, 1-15.

8. Marella, S.; Tollamadugu, N.V.K.V.P. Nanotechnological approaches for the development of herbal drugs in the treatment of diabetes mellitus-A critical review. IET Nanobiotechnol. 2018, 12, 549-556. [CrossRef]

9. Jahangir, M.A.; Taleuzzaman, M.; Kala, C.; Gilani, S.J. Advancements in Polymer and Lipid-based Nanotherapeutics for Cancer Drug Targeting. Curr. Pharm. Des. 2020, 26, 5119-5127. [CrossRef]

10. Jahangir, M.A.; Anand, C.; Muheem, A.; Gilani, S.J.; Taleuzzaman, M.; Zafar, A.; Jafar, M.; Verma, S.; Barkat, M.A. Nano Phytomedicine Based Delivery System for CNS Disease. Curr. Drug Metab. 2020, 21, 661-673. [CrossRef]

11. Namdari, M.; Eatemadi, A.; Soleimaninejad, M.; Hammed, A.T. A brief review on the application of nanoparticle enclosed herbal medicine for the treatment of infective endocarditis. Biomed. Pharmacother. 2017, 87, 321-331. [CrossRef]

12. Sadeghi, F.; Ashofteh, M.; Homayouni, A.; Abbaspour, M.; Nokhodchi, A.; Garekani, H.A. Antisolvent precipitation technique: A very promising approach to crystallize curcumin in presence of polyvinyl pyrrolidon for solubility and dissolution enhancement. Colloids Surf. B Biointerfaces 2016, 147, 258-264. [CrossRef]

13. Gilani, S.J.; Imam, S.S.; Ahmed, A.; Chauhan, S.; Mirza, M.A.; Taleuzzaman, M. Formulation and evaluation of thymoquinone niosomes: Application of developed and validated RP-HPLC method in the delivery system. Drug Dev. Ind. Pharm. 2019, 45, 1799-1806. [CrossRef]

14. Moolakkadath, T.; Aqil, M.; Ahad, A.; Imam, S.S.; Praveen, A.; Sultana, Y.; Mujeeb, M. Preparation and optimization of fisetin-loaded glycerol-based soft nanovesicles by Box-Behnken design. Int. J. Pharm. 2020, 578, 119125. [CrossRef]

15. Jain, P.; Taleuzzaman, M.; Kala, C.; Gupta, D.K.; Ali, A.; Aslam, M. Quality by design (Qbd) assisted development of phytosomal gel of aloe vera extract for topical delivery. J. Liposome Res. 2021, 31, 381-388. [CrossRef]

16. Sandhiya, V.; Ubaidulla, U. A review on herbal drug loaded into pharmaceutical carrier techniques and its evaluation process Future J. Pharm. Sci. 2020, 6, 51. [CrossRef]

17. Moghddam, S.M.; Ahad, A.; Aqil, M.; Imam, S.S.; Sultana, Y. Optimization of nanostructured lipid carriers for topical delivery of nimesulide using Box-Behnken design approach. Artif. Cells Nanomed. Biotechnol. 2017, 45, 617-624. [CrossRef]

18. Nagajyothi, P.C.; Minh An, T.N.; Sreekanth, T.V.M.; Lee, J.-I.; Lee, D.J.; Lee, K.D. Green route biosynthesis: Characterization and catalytic activity of ZnO nanoparticles. Mater. Lett. 2013, 108, 160-163. [CrossRef]

19. Prachi, A.M.; Mushtaq, A.; Patel, R.; Singh, N.; Negi, D.S.; Rawat, S. Green Synthesis of Zinc Oxide Nanoparticles using Rubia Cordifolia Root extract against different Bacterial Pathogens. Indo Am. J. Pharm. Res. 2017, 7, 759-765.

20. Ahmad, S.; Munir, S.; Zeb, N.; Ullah, A.; Khan, B.; Ali, J.; Bilal, M.; Omer, M.; Alamzeb, M.; Salman, S.M.; et al. Green nanotechnology: A review on green synthesis of silver nanoparticles-An ecofriendly approach. Int. J. Nanomed. 2019, 14, 5087-5107. [CrossRef]

21. Singh, R.P.; Shukla, V.; Yadav, R.S.; Sharma, P.K.; Singh, P.; Pandey, A.C. Biological approach of zinc oxide nanoparticles formation and its characterization. Adv. Mater. Lett. 2011, 2, 313-317. [CrossRef]

22. Nagajyothi, P.C.; Cha, S.J.; Yang, I.J.; Sreekanth, T.V.; Kim, K.J.; Shin, H.M. Antioxidant and anti-inflammatory activities of zinc oxide nanoparticles synthesized using Polygala tenuifolia root extract. J. Photochem. Photobiol. B Biol. 2015, 146, 10-17. [CrossRef]

23. Wang, D.; Cui, L.; Chang, X.; Guan, D. Biosynthesis and characterization of zinc oxide nanoparticles from Artemisia annua and investigate their effect on proliferation, osteogenic differentiation and mineralization in human osteoblast-like MG-63 Cells. J. Photochem. Photobiol. B Biol. 2020, 202, 111652. [CrossRef]

24. Mekjaruskul, C.; Sripanidkulchai, B. Kaempferia parviflora Nanosuspension Formulation for Scalability and Improvement of Dissolution Profiles and Intestinal Absorption. AAPS PharmSciTech 2020, 21, 52. [CrossRef]

25. Shirsat, A.E.; Chitlange, S.S. Application of quality by design approach to optimize process and formulation parameters of rizatriptan loaded chitosan nanoparticles. J. Adv. Pharm. Technol. Res. 2015, 6, 88-96. [CrossRef]

26. Bose, A.; Wong, T.W.; Singh, N. Formulation development and optimization of sustained release matrix tablet of Itopride $\mathrm{HCl}$ by response surface methodology and its evaluation of release kinetics. Saudi Pharm. J. 2013, 21, 201-213. [CrossRef]

27. Monajjemzadeh, F.; Hamishehkar, H.; Zakeri-Milani, P.; Farjami, A.; Valizadeh, H. Design and optimization of sustained-release divalproex sodium tablets with response surface methodology. AAPS PharmSciTech 2013, 14, 245-253. [CrossRef]

28. Rosenblatt, M.K.; Bunjes, H. Evaluation of the drug loading capacity of different lipid nanoparticle dispersions by passive drug loading. Eur. J. Pharm. Biopharm. 2017, 117, 49-59. [CrossRef]

29. Hao, J.; Gao, Y.; Zhao, J.; Zhang, J.; Li, Q.; Zhao, Z.; Liu, J. Preparation and optimization of resveratrol nanosuspensions by antisolvent precipitation using Box-Behnken design. AAPS PharmSciTech 2015, 16, 118-128. [CrossRef]

30. Sun, Y.; Tang, S.-F.; Gao, L.-Q. Optimization of the release of salicylic acid calibrator tablets in a flow-through cell with central composite design. Chin. J. Pharm. Anal. 2009, 29, 1243-1247.

31. Baláž, M.; Balážová, L'.; Daneu, N.; Dutková, E.; Balážová, M.; Bujňáková, Z.; Shpotyuk, Y. Plant-Mediated Synthesis of Silver Nanoparticles and Their Stabilization by Wet Stirred Media Milling. Nanoscale Res. Lett. 2017, 12, 83. [CrossRef] [PubMed]

32. Yadav, S.K.; Mishra, S.; Mishra, B. Eudragit-based nanosuspension of the poorly water-soluble drug: Formulation and In Vitro-In Vivo evaluation. AAPS PharmSciTech 2012, 13, 1031-1044. [CrossRef] [PubMed]

33. Kalvakuntla, S.; Deshpande, M.; Attari, Z.; Kunnatur, B.K. Preparation and Characterization of Nanosuspension of Aprepitant by H96 Process. Adv. Pharm. Bull. 2016, 6, 83-90. [CrossRef] [PubMed] 
34. Caputo, F.; Clogston, J.; Calzolai, L.; Rösslein, M.; Prina-Mello, A. Measuring particle size distribution of nanoparticle enabled medicinal products, the joint view of EUNCL and NCI-NCL-A step-by-step approach combining orthogonal measurements with increasing complexity. J. Control. Release 2019, 299, 31-43. [CrossRef]

35. Patel, V.R.; Agrawal, Y.K. Nanosuspension: An approach to enhance the solubility of drugs. J. Adv. Pharm. Technol. Res. 2011, 2 , 81-87.

36. Sathyamoorthy, N.; Magharla, D.; Chintamaneni, P.; Vankayalu, S. Optimization of paclitaxel loaded poly ( $\varepsilon$-caprolactone) nanoparticles using Box Behnken design. Beni-Suef Univ. J. Basic Appl. Sci. 2017, 6, 362-373. [CrossRef]

37. Patra, J.K.; Das, G.; Fraceto, L.F.; Campos, E.V.R.; Rodriguez-Torres, M.D.P.; Acosta-Torres, L.S.; Diaz-Torres, L.A.; Grillo, R.; Swamy, M.K.; Sharma, S.; et al. Nano-based drug delivery systems: Recent developments and future prospects. J. Nanobiotechnol. 2018, 16, 71. [CrossRef]

38. Dutta, S.; Ganguly, B.N. Characterization of ZnO nanoparticles grown in presence of Folic acid template. J. Nanobiotechnol. 2012, 10, 29. [CrossRef]

39. Taleuzzaman, M.; Sartaj, A.; Gupta, D.K.; Gilani, S.J.; Mirza, M.A. Phytosomal gel of Manjistha extract (MJE) formulated and optimized with central composite design of Quality by Design (QbD). J. Dispers. Sci. Technol. 2021. [CrossRef]

40. Gupta, M.; Tomar, R.S.; Kaushik, S.; Mishra, R.K.; Sharma, D. Effective Antimicrobial Activity of Green ZnO Nano Particles of Catharanthus roseus. Front. Microbiol. 2018, 9, 2030. [CrossRef]

41. Brand-Williams, W.; Cuvelier, M.E.; Berset, C. Use of a free radical method to evaluate antioxidant activity. LWT-Food Sci. Technol. 1995, 28, 25-30. [CrossRef]

42. Sahu, A.R.; Bothara, S.B. Formulation and evaluation of phytosome drug delivery system of boswellia Serrata extract. Int. J. Res. Med. 2015, 4, 94-99.

43. Moradi, S.Z.; Momtaz, S.; Bayrami, Z.; Farzaei, M.H.; Abdollahi, M. Nanoformulations of Herbal Extracts in Treatment of Neurodegenerative Disorders. Front. Bioeng. Biotechnol. 2020, 8, 238. [CrossRef]

44. Parekh, J.; Chanda, S. Research Papers In Vitro antimicrobial activity of Trapa natans L. fruit rind extracted in different solvents. Afr. J. Biotechnol. 2007, 6, 766-770.

45. Nayaka, H.B.; Londonkar, R.L.; Umesh, M.K. Evaluation of Potential Antifertility activity of Total Flavonoids, Isolated from Portulaca oleracea L on female albino rats. Int. J. PharmTech Res. 2014, 6, 783-793.

46. Lobo, V.; Patil, A.; Phatak, A.; Chandra, N. Free radicals, antioxidants and functional foods: Impact on human health. Pharmacogn. Rev. 2010, 4, 118-126. [CrossRef] 